\title{
Del sindicato a la central obrera en una trayectoria de provincia: Tucumán en los años 30
}

\author{
María Ullivarri
}

(CEIL-CONICET)

El principio de unidad sindical era un precepto rector de la acción de los trabajadores organizados en la provincia de Tucumán durante los años 30, un significante constantemente reivindicado en la prensa obrera y en la retórica cotidiana de las organizaciones. Pero materializarlo no era fácil, porque unirse implicó ceder y negociar y este proceso no se realizó sin dificultades ni conflictos. El mundo obrero tenía diferentes escalas de organización, disímiles estrategias y miradas políticas encontradas. Intentar aunar voluntades, ideologias y formas de acción exigía dejar de lado las aristas más rígidas que regían los principios de cada sindicato y desdibujar los objetivos ideológicos y tácticos de una minoría militante, en pos de ocupar espacios de poder en un colectivo más amplio y trazar estrategias de acción comunes entre los sindicatos.

Para la mayor parte de los dirigentes obreros tucumanos de aquella década, era "impostergable la existencia de un organismo central que concentre las fuerzas organizadas de los trabajadores de la provincia." ${ }^{1}$ Así, en determinadas circunstancias la necesidad de articularse se impuso y los trabajadores tucumanos traspasaron la instancia del discurso y la discusión y lograron sostener organizaciones de segundo grado, es decir, organizaciones que nucleaban sindicatos. En este artículo nos detendremos en las negociaciones llevadas adelante por los dirigentes sindicales tucumanos para consolidar espacios de unidad mayor y en las profundas tensiones y discusiones políticas que atravesaron esas construcciones unitarias. Haremos hincapié en los acuerdos locales, pero también en los nacionales, que de alguna manera respondian a la aspiración de una articulación obrera en clave nacional, dando cuenta de un proceso de transformación general en el mundo del trabajo organizado en el todo el país.

1. Manifiesto de la Sociedad de Artes Gráficas, El Orden, 18/05/1931. 
Partimos de suponer que en esa dinámica de alianzas se visibiliza mucho más que una negociación política provincial; en ella se concentran todas las variables puestas en juego en el universo sindical de la década. En esos espacios de unidad se dirimen las disputas entre partidos, las pujas de poder, locales y nacionales; también, los posicionamientos internacionales y los intereses de los sindicatos involucrados. Los acuerdos y los conflictos para organizarse fueron, en definitiva, la expresión organizativa de los cambios en el universo sindical del país que tendía a centralizar el poder en Buenos Aires y de sus disputas políticas internas y externas que se fueron reproduciendo en la provincia con diferentes matices. En esta escala micro, pueden observarse entonces las huellas y las tiranteces de un proceso más amplio de construcción sindical y política, donde el juego entre lo local y lo nacional (y lo internacional) fue dando forma al proceso de unidad tucumano.

\section{La búsqueda de una central obrera}

A mediados de los años 20 el universo de las centrales sindicales en la provincia de Tucumán se dividía entre la Federación Obrera Local (FOLT) anarquista, fundada en 1902; la Unión General de Trabajadores (UGT), surgida en 1904 como un desprendimiento socialista de la FOLT y un grupo de sindicatos autónomos que solía unirse en Comités de Relaciones. En ese concierto también la Unión Sindical Argentina (USA) había realizado esfuerzos por formar una Unión Obrera Local de la mano de la Alianza Libertaria Argentina. Sus éxitos fueron escasos porque según señalaba desde su órgano de prensa, "los sindicatos han venido retrasando esta obra" y continúan "aislados y dispersos." 2 Este análisis, sin embargo, no era exclusivo de la USA, porque a pesar de una existencia nominal de organizaciones, el escenario del trabajo organizado era muy acotado. Las propias miradas obreras eran raramente optimistas y remarcaban que "la situación porque atraviesa la organización obrera en esta ciudad no es floreciente, dicho sea en honor a la verdad. Los gremios que integran esta local están un tanto decaídos. Y por lo que se refiere a los autónomos no están en mejores condiciones". ${ }^{3}$

En una periferia con arraigados vicios de pequeña comunidad y poco industrializada fuera de la industria azucarera, fundar organizaciones, conseguir afiliados, plantear demandas y acciones no era una tarea sencilla. La FOLT, que era la mayor organización, sobrevivía con altibajos y no lograba disimular el pesimismo: "de seguir asî", decía en su órgano

\footnotetext{
2. El Trabajo, 25/03/1924.

3. Tierra Libre. Órgano oficial de la F.O. Local tucumana y oficioso de las organizaciones del Norte, agosto de 1925 (en adelante, Tierra Libre).
} 
de prensa, "seremos absorbidos por el ambiente hasta tal punto que no quedará nada después de tantos años de sacrificios". ${ }^{4}$ En esa dirección, en 1928 se disolvió la UGT y un año después la FOLT denunció que no tenía siquiera quién cubriera los cargos en su comisión directiva. El impulso unionista estaba en baja y los anarquistas llamaban a "sacar fuerzas de flaquezas, hasta levantar las organizaciones". ${ }^{5}$ Un tiempo después, el golpe de Estado de 1930 terminó de desarmar los impulsos de lucha y una suerte de impasse sindical silenció la protesta y la acción obrera. La FOLT fue la única organización de segundo grado que sobrevivió y lo hizo atrincherada en un "repliegue a la defensiva". ${ }^{6}$

Paralelamente, la conformación de la Confederación General del Trabajo (CGT) en septiembre de 1930 inauguraba un nuevo ciclo en la historia del movimiento obrero. Si bien no nucleó en un primer momento a la mayoría de los sindicatos, sí vino a ocupar un espacio destacado como referente de los trabajadores frente al Estado y la sociedad. ${ }^{7}$ Aunque su alcance era muy limitado, la central era también, o pretendía serlo, un eje de articulación entre las dirigencias obreras del país. ${ }^{8}$ Pero la CGT se había conformado en la ciudad de Buenos Aires y en tanto esta organización dilataba el llamado a un congreso constituyente y su Junta Ejecutiva era predominantemente porteña, no existieron espacios de discusión entre ella y los sindicatos provinciales. Las pocas fuentes encontradas que dan testimonio de los vínculos de esta organización con Tucumán durante la temprana década de 1930 acusan un marcado tono irónico y rescatan como acontecimiento notable la insistente demanda cegetista "del envío de cotizaciones". ${ }^{9}$ Fuera de ello, las referencias respecto a las acciones y la presencia de la CGT son esquivas.

En sus inicios contaba en Tucumán con nueve adherentes, ocho de ellos eran secciones de la Unión Ferroviaria (UF) y la restante era la seccional local de la Asociación de Trabajadores del Estado. ${ }^{10}$ De esta forma, su articulación local era muy débil, ya que todos sus cotizantes tucumanos estaban encuadrados en organizaciones nacionales. La central se había abocado en esos meses a "salvar al movimiento obrero del caos y la confusión", y como consecuencia sus vínculos con los

4. Tierra Libre, abril de 1929. En la FOLT se agrupaban los panaderos, mosaístas, carpinteros, zapateros, canillitas, albañiles, pintores, oficios varios y Brazo y Cerebro.

5. Tierra Libre, abril de 1929.

6. Tierra Libre, octubre de 1935.

7. Boletín del Trabajo, año 7, octubre de 1930.

8. Boletin CGT, 15/01/1932.

9. Tierra Libre, octubre de 1930.

10. Boletin CGT, 15/03/1932. 
sindicatos de la provincia no estuvieron entre sus prioridades. ${ }^{11}$ Recién en enero de 1932, una vez vislumbradas nuevas condiciones politicas y levantado el estado de sitio, la CGT intentó sembrar presencia en las provincias a través de giras para dar conferencias o colaborar con la fundación de uniones obreras. A Tucumán llegó el "delegado confederal" Domingo Heredia para organizar una conferencia a la que se invitó a concurrir a "albañiles, chauffeurs, gráficos, empleados de comercio, ferroviarios, municipales, carpinteros, pintores, telefónicos, fideeros, mozos, cocineros, etc.". Allí señaló "la necesidad urgente de organizar a los trabajadores en sus respectivos sindicatos y constituir la Federación Obrera Local". ${ }^{12}$

La propuesta cegetista no encontró interlocutores dispuestos a embanderarse atrás de ella, pero la organización de una central provincial no era un tema ajeno a los intereses de los sindicatos tucumanos. Un tiempo antes del arribo del delegado cegetista, a mediados de 1931, cuando la actividad sindical comenzó a reactivarse tras el golpe, se materializó el primer intento de la década para organizar una central obrera en la región. La Sociedad de Artes Gráficas invitó a todos los sindicatos a enviar delegados a una reunión para discutir un plan de unidad con marcada impronta sindicalista, "libre de ideologías y tendencias políticas", ya que "se erigirá únicamente con carácter gremial, única forma de mantener la integridad y unión de la representación obrera". ${ }^{13}$

Este primer proyecto llegó tan lejos como el congreso formativo le permitió. Realizado en el local del Sindicato de Luz y Fuerza, la propuesta de una central "desligada en absoluto de toda tendencia politica" fue en el clima sindical de la época una posibilidad irrealizable. Alli reunidos todos parecian convenir en fomentar la "unidad de la clase obrera", pero sobre esos comunes conciertos cada trabajador llevaba luego a su sindicato diferentes lecturas de esos encuentros y los desacuerdos para fundar la Federación Obrera fueron desdibujando gradualmente la vitalidad inicial con la que esa idea se instaló. Al año siguiente, y quizás a instancias de la "visita confederal", pero sin su aplomo, varios sindicatos confluyeron en un Comité Mixto de Gremios Autónomos (CMGA), que funcionaba de oficio como organización de segundo grado y que realizó varias reuniones, mítines y conferencias para informar sobre las ventajas de la unidad y planificar nuevamente la conformación de una central obrera. ${ }^{14}$

11. Boletin CGT, 15/01/1932.

12. La Gaceta, 27/01/1932

13. La Gaceta, 18/05/1931.

14. El Comité Mixto estaba compuesto por la Sociedad de Empleados y Obreros de Comercio, Sindicato de Obreros Fideeros, Artes Gráficas, Sindicato Unión Chauffeurs, 
A mediados de junio de 1932 se logró concretar una asamblea constitutiva que, en el marco de enardecidas controversias, intentó proyectar una declaración de principios. ${ }^{15}$ Las crónicas de la prensa informan que la reunión alcanzó "un tono un tanto violento" y fue finalmente boicoteada por "la tendencia comunista". Como había sucedido el año anterior, nuevamente los miembros del Partido Comunista (PC) intentaron impedir que se modificara un punto del borrador de la declaración de principios que, al sentir de la mayoría de las organizaciones, estaba "inspirado en principios de tendencia ideológica" y que, por lo tanto, no garantizaba que la central por conformarse "estuviera fuera de todo alcance político". ${ }^{16}$ La reunión pasó a cuarto intermedio, pero cada vez que los delegados intentaron reunirse la intensidad de las discusiones volvió a forzar la suspensión. Un mes después, el CMGA desapareció de las fuentes.

El espacio "autónomo", o que se erigía como tal, era una arena de disputas. Los militantes del PC, aglutinados en la Agrupación Pro Defensa Sindical, boicoteaban sistemáticamente todos los intentos de conformar centrales locales desligadas de luchas politicas, tanto locales como internacionales. En ese sentido, sus militantes apostaban a que fuera el propio Comité de Unidad Sindical Clasista el que llegase a convertirse en una central cuando estuviera preparado para ello a través del arraigo en las masas obreras. ${ }^{17}$ La CGT, por su parte, rechazaba "la existencia de sindicatos obreros "autónomos" puesto que [...] carentes del apoyo solidario, desaparecen con suma facilidad al menor amago reaccionario". ${ }^{18}$ Y por eso mismo estaba dispuesta a disuadir cualquier intento de conformar centrales autónomas.

Parte de lo que en realidad se discutía aquí era el tema de la política, o su contracara, la prescindencia. Y esa era una batalla que comenzaba a instalarse con fuerza, tanto adentro de la CGT, entre los sindicalistas y un sector del socialismo, a quien acusaban de "tener el deseo de acoplar

Sindicato de Mozos, Obreros Pintores, Obreros Panaderos autónomos, Sindicato Autónomo de Albañiles y anexos, Sociedad de Resistencia de Obreros Municipales, Sindicato Unión General de Ladrilleros de Alto de la Pólvora y de Villa Luján, Unión Linotipistas, Sindicato de Luz y Fuerza, Sociedad de Difundidores de Prensa y Unión Mimbreros.

15. La Gaceta, 20/06/1932.

16. La Gaceta, 20/06/1932.

17. "La situación de la clase obrera... (título completo ilegible)", Documento del Partido Comunista, junio de 1931, Legajo del PC, N³362, Fondo Agustín P. Justo, Archivo General de la Nación.

18. Boletin CGT, 25/06/1933. 
las actividades sindicales a la suerte de un partido político"; ${ }^{19}$ (Martínez, 2009) como afuera, con la presión de los comunistas. Estas tensiones ponían en discusión cotidianamente la estrategia cegetista, aquella que consistía en sostener el statu quo para defender a la organización de las posibles reacciones gubernamentales y patrocinar un equilibrio politico que amenazaba constantemente la asumida postura de prescindencia que parte de su dirigencia se esforzaba en sostener. En ese sentido, la postura de "autopreservación" habría sido el principal plan de acción de la CGT (Doyon, 2006).

Con el tiempo, el problema del fascismo y las bandas armadas, en donde los sindicatos reclamaba a la central que tome una postura enérgica, así como las demandas de un congreso constituyente y la cuestión de la prescindencia, fueron deteriorando los acuerdos posibles y sus tiempos políticos se cerraron (Del Campo, 2005; Matsushita, 1983). La CGT dio respuestas al tema del fascismo con un "Plan de Emergencia", pero fue demasiado tarde. ${ }^{20}$ Nada dijo sobre el congreso constituyente, mientras que la voluntad política de la central sindical siempre se pensó como un mecanismo de intervención para conseguir beneficios económicos, ubicando al movimiento obrero como un sector con intereses propios dentro de un orden que se aceptó como dado. No obstante, durante los años 30 parte del movimiento sindical iba tomando la decisión de proyectarse a la arena política cortando con la tradicional postura de "prescindencia" (Doyon, 2006) y la central quedó rezagada frente a esas demandas.

A fines de 1935 la conducción central fue cooptada por los sectores disconformes vinculados a la UF quienes tomaron por la fuerza el local de la calle Independencia (Matsushita, 1983). Este cambio provocó un reacomodamiento de los vínculos de la CGT con los gremios que la componian a partir de la voluntad manifiesta de dar constitución orgánica a la entidad llamando un congreso constituyente en 1936. Y aunque recién en 1938 se logró incorporar un dirigente tucumano al Comité Central Confederal (CCC) de la CGT, la central sí nombró inmediatamente un representante local, Emilio López -dirigente ferroviario y del PS-, quien comenzó a tomar parte activa en todas las acciones importantes del movimiento sindical tucumano.

Quedaba todavía en el aire la cuestión de la política, que fue un tanto más compleja de resolver. Eduardo Zimmermann (1985: 23) ubica en 1936 el momento donde se permeabilizaron las opciones políticas, cuando la CGT Independencia, recientemente dividida, escribió en sus estatutos que "debia intervenir constantemente en todos los problemas

19. Boletin CGT, 25/10/1933.

20. CGT, 22/06/1934 y 20/07/1934. 
nacionales que afecten a los trabajadores". Pero si bien fue la crítica al apoliticismo uno de los argumentos centrales de la ruptura de la CGT en 1935, la nueva conducción, para desarticular la presión comunista, volvió a fijar un rumbo prescindente (Camarero, 2011).

\section{La unidad con sello local. La Federación Provincial de Trabajadores}

En Tucumán, como en el resto del país, a partir de la segunda mitad de los años 30 se produjo un notable crecimiento del movimiento obrero y, consecuentemente, de su voluntad de ocupar un rol nodal en la escena politica del país (Matsushita, 1983; Horowitz, 2004; Murmis y Portantiero, 2004; Del Campo, 2005; Doyon, 2006; Torre, 2006). En ese contexto se creó en 1936 la Federación Provincial de Trabajadores (FPT). Esta central obrera fue producto de varios intentos fallidos por articular las organizaciones gremiales de la provincia. Por lo tanto, su conformación definitiva puede ser entendida como un paso destacado en la maduración de la estructura sindical tucumana que, de alguna manera, acompañaba el crecimiento de la misma estructura a nivel nacional signada por el crecimiento de la matriz organizativa del sindicalismo, especialmente con la creciente influencia comunista, el trabajo del socialismo y el afianzamiento de la CGT (Matsushita, 1983; Del Campo, 2005; Doyon, 2006; Torre, 2006).

No obstante, un proceso de unidad sindical no es unicausal. En ese sentido, el crecimiento sindical y la constitución definitiva de la CGT luego del Congreso Constituyente de marzo de 1936 no pueden pensarse como acontecimientos ajenos a la creación de una central obrera en la provincia. Sin embargo, no reconoce allí sus únicos impulsos. En ella tuvieron influencia múltiples factores que funcionaron como acontecimientos disparadores de solidaridades, alianzas y movilizaciones. El universo político que acompañó la asunción de gobiernos radicales en la provincia y un contexto internacional de movilización antifascista desprendido de la Guerra Civil Española abrieron nuevas posibilidades para retomar las conversaciones..$^{21} \mathrm{El}$ aumento de la conflictividad obrera, el auge de los comités de lucha contra el fascismo, la política de frentes populares que se capilarizaba internacionalmente y el lugar destacado que en esos frentes estaban ocupando los trabajadores, fue-

21. En 1934 una fracción de la UCR denominada Concurrencista se presentó a elecciones desoyendo los mandatos abstencionistas del Comité Nacional. El triunfo de los radicales en la contienda electoral convirtió a Tucumán en una de las tres provincias argentinas que durante la década del 30 estuvo gobernada por la UCR (Ullivarri, 2010). 
ron también agentes capitales en la idea de sostener una estrategia de unidad a largo plazo. ${ }^{22}$

En ese contexto, el sindicato que agrupaba a los trabajadores del volante conformó un "Comité Pro Central Obrera" que empezó a tener intervención en los conflictos gremiales de la provincia, canalizando la solidaridad de otros sindicatos. En un escenario donde las luchas se aceleraban, esta suerte de espacio de unidad tuvo la particularidad de no disolverse luego de los conflictos, sino que fue abocándose a nuevas actividades, como las colectas para la República Española. En octubre de 1936 salió de este Comité la propuesta de realizar un "congreso de gremios". El congreso se realizó en el local de la Sociedad de Empleados y Obreros de Comercio (SEOC) y el 18 de noviembre, luego de dos días de deliberaciones, la Federación Provincial de Trabajadores (FPT) quedó organizada con veinte delegados de doce organizaciones gremiales. ${ }^{23}$

La incapacidad de mantener los objetivos unitarios por largo tiempo había sido un problema arraigado dentro de las relaciones intergremiales de la provincia. De manera que apenas conformada, la Federación tuvo que enfrentar algunas dificultades. Las fuentes no son claras respecto a la naturaleza de las diferencias existentes entre las organizaciones e informan que algunas entidades no concurrian a las reuniones -como la UF- o se mostraban apáticas respecto a las posibilidades de éxito que la FPT podía llegar a tener -como Luz y Fuerza-. No obstante, luego de enconosos debates y asambleas, la central obrera se materializó definitivamente en julio de 1937 cuando los gremios participantes decidieron dar término a las complejas negociaciones, nombrando una Comisión con los presentes en la reunión y enviando por nota la solicitud de delegados a los sindicatos ausentes. ${ }^{24}$

La Federación no fue, en términos generales, una entidad autónoma sino el nombre que asumió el espacio de negociaciones intergremiales en la provincia. Fue un punto de superposición de intereses comunes, donde las disputas políticas se dirimian entre los gremios locales y la puja de poderes respetaba la capacidad de movilización de cada organización. Esta tomó a su cargo la dirección de una parte mayoritaria

22. Entre 1935 y 1936 se produjeron 34 huelgas y doce conflictos laborales importantes.

23. En el congreso constituyente estaban representadas la SEOC, los chauffeurs, los vidrieros, los obreros de la madera, las costureras, los albañiles, Luz y Fuerza, los sastres, los municipales, las artes gráficas, la UF y La Fraternidad.

24. La Comisión Administrativa quedó compuesta por Doroteo Lescano por SEOC, S. Díaz por el Sindicato Unión Chauffeurs, Carlos Poluica por el Sindicato de Obreros Vidrieros, Francisco Fernández por el Sindicato de la Madera, Carmen Valverdi por la Sociedad de Obreras Costureras y dos delegados de los sindicatos de Luz y Fuerza y Albañiles. La Gaceta, 21/07/1937. 
del movimiento obrero provincial y también, a través de la conservación de los rituales y la organización de los espacios simbólicos que modelaban la experiencia obrera, actuó como el resguardo de los valores y los emblemas de un segmento de la clase trabajadora tucumana. En ese sentido, una de sus actividades matrices fue la organización del $1^{\circ}$ de mayo. Bajo su auspicio se conformó en 1937 un Comité Pro Primero de Mayo que, posteriormente, se convertiria en un espacio estable de organización. El fundamento de este comité era articular a los representantes de agrupaciones gremiales, organizaciones sociales y partidos políticos de la provincia, con el objeto de celebrar la fecha "bajo un aspecto social-político nuevo", con el sello de los aires frentepopulistas que cautivaban a gran parte del planeta. ${ }^{25}$

Mientras se bosquejaban los preparativos, el comité lanzó un manifiesto a las calles expresando la expectativa por la consecución de un anhelo que ahora hacian propio, la unidad de todos los sectores con un fin mucho más profundo que aquel que sólo reivindicaba mejoras económicas. La idea era congregar "por primera vez en Tucumán [...] en una sola manifestación a los sindicatos obreros y a los partidos democráticos [...] una tregua a las diferencias de carácter ideológico [...] aspiran (do) a convertir en realidad social la libertad politica, la igualdad económica y la paz universal". ${ }^{26}$ Esta celebración implicaba, de alguna manera, la presentación oficial de la Federación y los anhelos de unidad marcaron su impronta.

Algunos sindicatos le brindaron su apoyo específico, como el de la Madera, que desde un manifiesto expresó que "ésta (la FPT) debe ser la entidad llamada a representar a los obreros". ${ }^{27}$ Sin embargo, otras organizaciones no estuvieron tan francamente dispuestas a colaborar. En parte porque el momento en el que se inscribieron todos estos deseos fue atravesado por las dificultades internas del socialismo local (Ullivarri, 2008). En este sentido, para un sector disidente -que luego sería el Socialismo Obrero (PSO) -el Comité Pro Primero de Mayo era una base firme para la constitución del Frente Popular. Y al igual que para el PC, los esfuerzos debían dirigirse "hacia la continuidad de las tareas de ese comité para que constituya el elemento coordinador de todas las simpatias que en el pueblo y las organizaciones existen para la conjunción de las fuerzas democráticas y obreras". ${ }^{28}$

25. La Gaceta, 26/04/1937.

26. La Gaceta, $17 / 04 / 1937$.

27. La Gaceta, 29/04/1937.

28. Los disidentes, que luego conformarian el Partido Socialista Obrero, habian ganado las elecciones para la Junta Ejecutiva en 1936 y fueron acusados de fraude provocando la intervención de la Federación (Ullivarri, 2008). 
El carácter marcadamente político que revelaban sus apoyos puso en alerta al PS. Su Junta Ejecutiva respondió que solo constituiría un Frente Popular "con agrupaciones responsables y partidos orgánicos", ${ }^{29}$ apuntando directamente a la situación de "ilegalidad" de los disidentes (PSO) y a la carencia de un "programa democrático" del PC. Por esa razón, los afiliados fieles al PS y el delegado cegetista organizaron rápidamente su propia celebración abandonando el comité organizado por la FPT.

El accidentado debut de la Federación visibilizó los desencuentros entre partidos y militantes que actuaban en el campo obrero. Sin embargo, logró sostenerse porque todos los gremios, incluso los simpatizantes socialistas, repudiaron la actitud del PS señalando que era "una verdadera conspiración contra la clase trabajadora de Tucumán y significa una clara definición de los móviles contrarios a la unidad democrática que los inspira". ${ }^{30}$

Luego de la conmemoración, el Comité se puso a trabajar en la creación del Frente Popular cuyo fin sería "defender los derechos obreros, las libertades individuales y la pureza del comicio en la próxima contienda electoral". ${ }^{31}$ Manifestaciones como ésta consolidaron aún más la impronta política en el movimiento obrero y dieron muestra acabada de que la prescindencia, tal como la entendía la dirección cegetista y el PS, ya no constituía una opción para un sector importante del movimiento obrero tucumano. El resultado de las asambleas, aunque el Frente no prosperó, fue fructífero para los dirigentes obreros, pues allí se debatieron también los apoyos a las candidaturas para las elecciones presidenciales de 1937 desde un encuadre diferente al sindical. De esta forma, aunque no asumían un compromiso político claro a nivel local, ni tampoco lo hacian en nombre de sus organizaciones de pertenencia, estos dirigentes sí esgrimieron su voluntad de colaboración con la fórmula opositora, el binomio Alvear-Mosca.

No fueron todos, sino aquellos dirigentes obreros vinculados al PC y al PSO quienes se pronunciaron en consonancia con los miembros de la UCR que participaban del Comité Pro Frente Popular. Así, aunque no sin reparos, para estos sindicalistas ésta era la forma más práctica de trabajar por la creación de condiciones necesarias para la realización del

\section{El Orden, 02/05/1937.}

30. La Gaceta, 21/04/1937. En tal sentido, fueron SEOC y la Unión Ferroviaria los más afectados porque en su seno convivian militantes de una y otra tendencia. Para otros sindicatos como la Sociedad de Resistencia de Obreros Sastres y la Sociedad de Obreras Costureras de Confección, el tránsito fue más armónico porque su dirigencia apoyó firmemente la propuesta del PSO.

31. La Gaceta, 15/05/1937. Cumpliendo con los mandatos de amplitud del Frente Popular, el comité designó a varios miembros de la UCR, abogados destacados, sindicalistas, miembros del PC y del PSO, para que organicen una asamblea constitutiva. 
Frente Popular, articulando al movimiento obrero con otros sectores de la sociedad..$^{32}$ El PS y sus sindicatos afines (UF, La Fraternidad y SEOC) se mantuvieron al margen, dispuestos a enfrentar a sus competidores desde una suerte de discurso moral que no parecía cuajar demasiado hondo en las estructuras ya construidas. En ese sentido, su avance político y militante parecía haberse estancado, y esta situación fue aprovechada por otras fuerzas politicas y sindicales para operar dentro del espacio de unidad que constituía la FPT.

En ese sentido, por fuera de los espacios rituales y de algunas intervenciones exitosas en la negociación de conflictos, la Federación todavía era una idea en construcción y estaba, por eso mismo, colmada de dificultades. Una de ellas era que todos los procedimientos debian hacerse ad referendum de las respectivas asambleas de los gremios que la integraban. Y aunque esta conformación permitía a los sindicatos manejar el consenso federativo, quitaba autonomia a sus decisiones y generaba demoras en las gestiones. Por eso, los sindicatos cercanos al PSO y al PC salieron a disputar ese espacio de negociaciones y luego de varias deliberaciones lograron dar un paso más en la conformación de la central, reorganizándola con mandato imperativo a sus delegados y estipulando un monto para las cotizaciones. Luego de la modificación estatutaria, los militantes socialistas fueron desplazados de la Comisión Administrativa. ${ }^{33}$

Esta impronta le dio mayor presencia a las acciones de la FPT en el marco de la renovada autonomía adquirida y de los fondos recibidos, porque la federación ganó el ritmo de los gremios más combativos. Dejó entonces de actuar solamente como gestora de celebraciones, comités de huelga o articuladora de gremios obreros, para pasar a representar los intereses de los trabajadores. De esta forma, a través del mandato imperativo de sus delegados, asumía como propias las consignas de todo el movimiento sindical: la lucha contra la desocupación, la reforma del Departamento Provincial de Trabajo (DPT), el cumplimiento estricto de la legislación obrera y la pronta sanción de una ley de trabajo a domicilio. ${ }^{34}$ Asimismo, colaboró en la fundación de organismos urbanos

\section{La Gaceta, 08/05/1937.}

33. En 1939 fueron electos para la Comisión Administrativa Manuel Fernández (Sastres y PSO), Manuel Espinosa (Construcción y PC), Miguel Oscar Reinoso (Sindicato de la Carne), Albino Vischi (SEOC y PSO), Miguel Carabajal, Estanislao Terra (SEOC) y Ernesto Biassi (Madera y PC). La Gaceta, 14/08/1939.

34. El DPT fue creado por un decreto. Al no tener carácter de ley, sus facultades para hacer cumplir las normas y aplicar multas fueron constantemente negadas. Su función, tal como la relatan sus directores, era la de "amigable componedor." Departamento Provincial del Trabajo. Memoria anual, 1925, Archivo de la Legislatura de la Provincia de Tucumán. 
e incursionó en un sector complejo: la industria azucarera, que era territorio socialista.

Los gremios socialistas, sin embargo, no se quedaron a la zaga y desde sus tribunas comenzaron a exigir una nueva reorganización unitaria alineada más directamente con la CGT. Los apologistas de esta idea no veían con buenos ojos la estampa comunista y socialista obrera que la dirección de la FPT había adquirido y, en consecuencia, especulaban con la posibilidad de que una mayor presencia regional de la CGT les brindara un soporte más sólido para posicionarse localmente. En ese sentido, antecedentes de demandas que apuntaban a fortalecer el vínculo de la CGT con el movimiento sindical tucumano pueden rastrearse en los discursos de los dirigentes de la UF, SEOC, La Fraternidad y posteriormente los Cerveceros, que en numerosas ocasiones reiteraron la necesidad de conformar una entidad que en la provincia nucleara a la FPT y a los gremios autónomos bajo la égida de la Confederación "como medida más eficaz para consolidar la unidad del proletariado argentino". ${ }^{35}$

Así, luego del primer Congreso Ordinario Confederal de la CGT en 1939 dos cambios se hicieron evidentes. ${ }^{36}$ En primer lugar, la central estableció como prioritario organizar a los trabajadores del azúcar, que componían el sector mayoritario de clase trabajadora tucumana. Por otro lado, los gremios "cegetistas", en conjunto con el trabajo intenso del representante local, Emilio López, comenzaron a visibilizar y sostener la "presencia institucional" de la CGT y su Plan de Acción, y lo hicieron a través de actos, presionando continuamente para materializar la idea de una representación local y enviando notas al semanario nacional, que eran publicadas en página completa. ${ }^{37}$

\section{De lo local a lo nacional: la Comisión Cooperadora de la CGT}

A partir del segundo lustro de los años 30 el incipiente movimiento obrero tucumano fue tomando una forma más nítida y esto dio un impulso más fuerte a la acción colectiva y la demanda. El aumento de la actividad obrera quedó plasmado en una mayor conflictividad, pero también en la intensificación de una trama de alianzas y construcciones más amplias con base regional y nacional (Del Campo, 2005; Matsushita, 1983; Kindgard, 2000; Di Tella, 2003; Camarero, 2012). En efecto, los vínculos tanto a nivel regional como nacional, que comenzaban a

35. La Gaceta, 24/05/1939

36. CGT, 25/08/1939.

37. CGT, 25/08/1939, 01/09/1939, 08/09/1939 у 15/09/1939. 
construirse por intermedio de delegados con mandato para organizar, gestionar o hacer propaganda gremial, fueron profundizándose. La $\mathrm{Fe}-$ deración Obrera de la Alimentación (FOA), la Confederación General de Empleados de Comercio (CGEC), la Federación Obrera Nacional de la Construcción (FONC), la Federación Nacional de Obreros de la Madera, la Federación de Obreros Cerveceros y Afines, La Fraternidad y la UF enviaban con asiduidad sus delegados a la provincia. Algunos daban conferencias, brindaban información sobre los beneficios de formar parte de una organización nacional, acompañaban en los conflictos y negociaciones o, como destacó un enviado del Sindicato Único de Obreros de la Madera, iban a "plantear la necesidad de unificar en toda la nación las fuerzas del gremio en un sindicato de industria". ${ }^{38}$

En el mismo tono, la estructuración nacional y regional de los sindicatos también parecía imponer o necesitar una representación local de segundo grado que tenga vínculos más estrechos con Buenos Aires. Consciente de estas demandas de los sindicatos tucumanos y de la necesidad de contar con ellos para asegurar el éxito del plan de acción, la CGT comenzó a enviar con más frecuencia delegados a la provincia. Primero llegó Francisco Pérez Leirós, quien expresó su fe en que "el norte no tardará en hacerse representar dignamente en la Confederación, para que al acrecentar la entidad su poderio, esté en condiciones de luchar con más probabilidades de éxito por las conquistas obreras". ${ }^{39}$ Posteriormente llegaron varios enviados buscando información, datos y estadísticas sobre "los problemas que afligen al obrero del interior". ${ }^{40}$

Sin embargo, la lucha obrera en la provincia seguía siendo sostenida por la FPT. Esta federación habia organizado y dirigido huelgas, trabajado mano a mano con fracciones de la UCR, se había entrevistado con funcionarios del gobierno, y había ido abriendo espacios en el interior de la provincia y en los territorios azucareros. No obstante, a mediados de 1940 empezó a tener algunos reveses y, luego de dos huelgas complejas, ${ }^{41}$ las falencias de la organización comenzaron a ser planteadas desde adentro. Esos conflictos visibilizaron especialmente los inconvenientes de acotarse a lo regional en un escenario donde urgian estrategias nacionales, especialmente porque los sindicatos locales ya estaban comenzando a fortalecerse en una organización por industria y las empresas radicadas en la provincia tenían sus casas centrales en

38. La Gaceta, 23/05/1936.

39. La Gaceta, $07 / 11 / 1939$.

40. La Gaceta, 27/03/1941.

41. Una de ellas fue la huelga de los obreros del matadero frente a la Municipalidad que comenzó a tener ribetes profundamente políticos y la otra, la de los cerveceros contra el grupo Bemberg que finalmente se solucionó en Buenos Aires (Ullivarri, 2010). 
Buenos Aires. Alli entonces, la convicción de que era prioritario extender la sindicalización y la necesidad de articular más sólidamente la unidad cerrando filas con la que era la organización más importante de los trabajadores argentinos, la CGT, quedó planteada en el seno de la FPT.

En esa puja también adquirían sentido las "incomodidades" que la firma del acuerdo de no agresión alemán-soviético habían provocado entre los dirigentes cercanos al PC y que arrastraban también a la FPT. La situación era tensa y los desencuentros politicos alcanzaron su pico más alto en 1941, cuando el PS exigió al Comité Pro Primero de Mayo "repudiar y combatir a los instrumentos y agentes que actúan en el medio argentino y que pretenden sembrar la confusión en el seno del pueblo y de la clase trabajadora". ${ }^{42}$ El PC y sus sindicatos afines eran los fehacientes destinatarios del mensaje porque, tal como continuaban esgrimiendo los socialistas, "todos estos fundamentales y elevados propósitos no podrán ser cumplidos en el Comité por la influencia que en el mismo ejercen aquellos que responden a las directivas de Moscú". Desde el Comité, no obstante, señalaron que el Partido Socialista intentaba "convencer al pueblo de que conviene a los argentinos dejarse arrastrar a una guerra entre grupos capitalistas rivales que se disputan el dominio del mundo". ${ }^{43}$ Aunque firmado a miles de kilómetros, las derivaciones de este pacto materializaron las excusas necesarias para poner nuevamente sobre el tapete los profundos desacuerdos ideológicos -pero también personales- que venían dando forma al mundo sindical de la provincia. De esta forma, la tensión entre partidos se dirimió más abiertamente en el escenario gremial cruzando acusaciones entre dirigentes y operando sobre las construcciones colectivas. Las lógicas internacionales tenian sentido solo porque en esa clave se leía también la puja de poderes locales.

Otra vez, sin embargo, los sindicatos tucumanos continuaron formando parte del Comité Pro Primero de Mayo junto al PC, conservando sus rituales y sus prácticas. En un escenario donde los militantes sindicales y partidarios eran, en la mayoría de los casos, las mismas personas, la debilidad de los partidos se acrecentaba en las disputas por los espacios. Los miembros más activos del socialismo salian con frecuencia a aclarar en la prensa que compartían actos con el PC en nombre de su sindicato y no del partido. Por su parte, los miembros del PC se veían obligados a negociar espacios con los gremios "cegetistas" que fueron desplazando a la dirigencia pro soviética de las tribunas. Las consecuencias de estas disputas internas no fueron menores y desgastaron los esfuerzos obreros por sostener la Federación, que desapareció como espacio de

42. La Gaceta, 29/04/1941

43. La Gaceta, 01/05/1941. 
encuentro. Un último esfuerzo por enfrentar la impronta de los sindicatos "cegetistas" fue realizado por varias organizaciones vinculadas al PSO y al PC, quienes intentaron fundar un "Comité de Relaciones" en forma provisoria, con plan de acción y estatutos, donde planeaban boicotear los intentos de la CGT de articular a todos los gremios de la provincia. ${ }^{44} \mathrm{Y}$ aunque se enviaron invitaciones a gremios autónomos y se realizaron varias reuniones, la iniciativa no prosperó.

Los gremios "cegetistas", a quienes se habian sumado los Cerveceros, supieron equilibrar los espacios de representación gremial de clase con sus preferencias políticas y fueron desgastando desde adentro a la FPT. Ya sin una central que opusiera resistencia, la presencia de la CGT era un hecho. A principios de 1941 Francisco Pérez Leirós y Mariano Cianciardo llegaron a la provincia para dar textura final a la organización local. Así, luego de un período de intensa propaganda, el 3 de julio de 1941 se constituyó en la ciudad una Comisión Cooperadora (CC) de la CGT con dirección exclusivamente socialista-cegetista. ${ }^{45}$ Su misión era realizar tareas de organización y propaganda y estaba destinada a mejorar las "condiciones morales y materiales de la clase trabajadora" ${ }^{46} \mathrm{Su}$ plan de trabajo tenía como prioridad organizar a los obreros del campo y a los pequeños productores de hasta 500 surcos; ${ }^{47}$ vincular a los gremios autónomos con la Comisión Cooperadora, colaborar en el armado sindical de algunas ramas urbanas, definir acciones para combatir el agio; determinar la financiación de gastos y conseguir la reforma del DPT, tareas que, en algunos casos, ya había comenzado a realizar la Federación Provincial de Trabajadores. ${ }^{48}$

Buscando llevar adelante la parte más importante de su plan, la construcción de una base sólida en la industria azucarera, los delegados de la CGT se instalaron en la campaña. En plena época de zafra, fueron recibidos con entusiasmo por los obreros y sus familias, pero también por los pequeños cañeros quienes agasajaron en cada pueblo

44. Participaron de él once organizaciones gremiales, entre ellas los sindicatos de sastres, construcción, de la carne, madera, costureras, chauffeurs, obreros y empleados del Estado, entre otros. La Gaceta, 14/06/1941.

45. CGT, 04/07/1941. En la reunión estuvieron presentes la UF, La Fraternidad, los cerveceros, SEOC y la Unión General de Trabajadores de la Industria Azucarera. Fue presidida por el delegado de la CGT Emilio López. La mesa directiva quedó conformada de esta manera: Secretario General: Doroteo Lescano (SEOC), Prosecretario: Gregorio Moreno (cerveceros), Secretario de actas: Héctor Argañaraz (SEOC) y Tesorero: José A. Juárez (LA Fraternidad CA)

46. La Gaceta, 17/07/1941.

47. De acuerdo al censo cañero de 1945 las plantaciones hasta 500 surcos -10 hectáreas aproximadamente- conformaban el $89 \%$ del total de plantadores.

48. La Gaceta, 07/07/1941. 
a sus representantes. A estos últimos los pretendia organizar "bajo su dirección y control a fin de que en el futuro puedan realizar una acción armónica y seria en procura de sus más sentidas reivindicaciones". ${ }^{49}$ Por tal motivo, en los actos y mitines organizados durante la estadia de los representantes porteños, el problema cañero- industrial, antes lejano a las preocupaciones nucleares de los obreros tucumanos, cobró una centralidad inusitada. Pérez Leirós fustigó en cada conferencia la desigualdad de ganancias que los industriales obtenian en detrimento de los pequeños cañeros. ${ }^{50}$ Esta preocupación cegetista era, no obstante, continuadora de un trabajo que habían comenzado un año antes la FPT y que se resumía en la idea de que, como señaló un dirigente de esa organización, los trabajadores no debian ni podian "permanecer indiferentes en la lucha que se libra entre industriales y cañeros", ${ }^{51}$ porque en esa contienda también se debatían fuentes de trabajo en un escenario donde la desocupación crecia. ${ }^{52}$

Pero a pesar de su intensa actividad, la CC no se instaló sin dificultades en el mundo gremial tucumano. Fueron varias las organizaciones que rechazaron las invitaciones enviadas o no asistieron a actos organizados para lograr agremiaciones, esgrimiendo diferencias con la entidad convocante. ${ }^{53}$ La CGT no era una organización con arraigo local y demandaba cierto compromiso que no todos estaban dispuestos o podian aceptar. Por ejemplo, se exigía la afiliación y cotización inmediata a la central para formar parte de la CC y, hasta tanto pusieran en regla su situación, las organizaciones que quisieran nuclearse eran aceptadas solo en "carácter fraternal", tal como le fue ofrecido a la Sociedad de

49. La Gaceta, 12/09/1941. Algo parecido había realizado la CGT con los pequeños agricultores del Chaco y con los viñateros de Mendoza. Cfr. CGT, 18/05/1934, 26/02/ 1936 y 05/03/1936.

50. Para la dirigencia de la CGT eran muy pocas las personas que se benefician de esta industria férreamente protegida por el Estado. Sin embargo, en la provincia muchas veces los delegados se encargaban de matizar esta postura. En ese sentido, Pérez Leirós afirmó que en realidad no le importaban "las pocas personas que resultan beneficiadas por la industria azucarera, sino los miles de trabajadores que resultan afectados por las injustas condiciones de vida que soportan." CGT, 01/05/1942 y La Gaceta, 29/06/1941.

51. Las pruebas de la voluntad solidaria de las organizaciones obreras con los cañeros quedó plasmada en una nota que la FPT envió al gobernador solicitándole su gestión "para solucionar la situación de numerosos cañeros afectados por el bajo precio del excedente de la caña, conforme ofrecen los industriales la situación que al propio tiempo afecta a los obreros". La Gaceta, 04/09/1940.

52. DNT, Investigaciones sociales, Buenos Aires, 1941.

53. Entre los que rechazaron la invitación se encuentran: Sindicato de Mozos, Sociedad de Vendedores de Diarios y Revistas, Sindicato de Obreros de la Unión Telefónica y Luz y Fuerza. La Unión, 21/10/1942. 
Artes Gráficas que era uno de los gremios más antiguos de la provincia y con mayor trayectoria local.

En un principio, la CC solo se conformó con las seis organizaciones con militantes socialistas/cegetistas, pero luego de la invasión alemana a la URSS y una vez fracasado el plan de una central paralela, su deseo por reinsertarse políticamente e instalarse "nacionalmente" llevó a los gremios comunistas como el de la Construcción, la Madera y el de Obreros y Empleados del Estado a solicitar su incorporación a aquella Comisión. A pesar de ser aceptados, todavía algunos sectores que dirigian la CGT local tenían el anhelo de constreñir la influencia del PC entre los trabajadores. De esta forma, la CC desconoció los sindicatos comunistas que se estaban fundando en las zonas azucareras y exigió su inmediata disolución en vistas de que "ya contaba la provincia con un organismo que nucleaba a los trabajadores del azúcar". ${ }^{44}$

La lealtad de los numerosos trabajadores del azúcar y de los pequeños campesinos cañeros era, en efecto, un "botín suculento" tanto para los socialistas -agrupados en la Unión General de Trabajadores de la Industria Azucarera (UGTIA) y la CC de la CGT- como para los comunistas -agrupados en la FOA-, que rivalizaban por un terreno que prometía enormes beneficios para negociar espacios sindicales tanto provinciales como nacionales. Era, por otro lado, más que una disputa numérica, ya que simbólicamente los trabajadores azucareros era el "alma y nervio" de la producción tucumana. Esta disputa quedó aún más en evidencia cuando el delegado de la FOA aprovechó su estadía en la provincia para profundizar la estructura sindical adherida a esa federación fundando organizaciones azucareras en varios pueblos azucareros, desafiando a la CC y afirmando la idea de conformar una federación paralela a la UGTIA.

Los espacios de unidad eran escenarios de resistencias encontradas que ahora se proyectaban nacionalmente. En términos de organización gremial, si bien la FTP había estado afiliada a la CGT, no dejaba de ser un espacio regional, donde el balance del poder sindical dirimía las contiendas ideológicas a nivel local y que de alguna manera resguardaba las tradiciones, las trayectorias y los recorridos de las organizaciones tucumanas. Al constituirse la CC en la ciudad y en el afán de nacionalizar el problema obrero y articularse extrarregionalmente, la organización intersindical tucumana perdió autonomía frente a las directivas de Buenos Aires y, del mismo modo, se desdibujaron los itinerarios recorridos y las historias sindicales de los gremios con tradición en la provincia, para fortalecer otros, más articulados nacionalmente.

Un tiempo después, los enfrentamientos que tensionaban al movi- 
miento obrero desde mediados de los años 30 se hicieron evidentes en el Segundo Congreso de la central (Matsushita, 1983) y tuvieron a la CC local en vilo. Pero en marzo de 1943, en las elecciones para el cuerpo directivo en el seno del CCC de la CGT, las dos listas enfrentadas se proclamaron ganadoras. ${ }^{55}$ La proclamación de autoridades había dejado espacios oscuros y nadie en Tucumán sabía muy bien a qué atenerse. Domenech insistía en la "conspiración comunista" y en la necesidad de respetar el Estatuto de la central, mientras que frente a él, un conjunto de dirigentes destacaba la urgencia de contar con una dirección "que comprenda los problemas políticos" del país. ${ }^{56}$

La presión por lograr adhesiones era continua y a Tucumán comenzaron a llegar comunicados de ambas listas. En una conferencia brindada por Ángel Borlenghi en la provincia se denunció que las maniobras de la CGT $\mathrm{N}^{\circ} 1$ apuntaban a reforzar la idea del peligro comunista con el fin de desprestigiar a la lista opositora. Días después, llegaron a la provincia delegados de Salta que corroboraron los dichos del dirigente mercantil al informar que el miembro de la CGT Roberto Testa, en gira por el norte, habia amenazado con presentar una nota a la patronal de comercio y también a la Iglesia Católica sugiriendo la presencia de comunistas y la necesidad de conformar entonces una nueva organización (Borlenghi, 1943). El comunismo era, en definitiva, el brazo más vigoroso y activo del movimiento obrero pero, al mismo tiempo, la "damisela" con la que nadie quería bailar.

Luego de una etapa de dudas y una suerte de temporada de alegatos, la división a nivel nacional comenzó a tener repercusiones en la provincia. Sin embargo, estas no fueron tan predecibles. El sólido bloque "socialista cegetista" de La Fraternidad, SEOC y los azucareros se unieron a los "comunistas" del Sindicato de la Construcción y el Sindicato del Vestido, ubicándose del lado de Pérez Leirós -lista $\mathrm{N}^{\circ} 2-$. Del otro lado, en cambio, los apoyos fueron menores: la Unión Ferroviaria y los cerveceros se solidarizaron con Domenech. Las líneas divisorias que venían disputando espacios desde los años 30, "socialistas versus comunistas y socialistas obreros" o "FPT versus cegetistas", se modificaron. Las nuevas alianzas surgidas de la división revelan también los cambios en la disputa política interna entre partidos y sus sindicatos simpatizantes. No fue solamente el juego de alianzas el que habia cambiado nacionalmente, sino también las nuevas miradas sobre el vínculo

55. En las elecciones para el CCC se presentaron dos listas, una encabezada por Domenech (Lista $\mathrm{N}^{\circ} 1$ ) y la otra por Pérez Leirós (Lista $\mathrm{N}^{\circ} 2$ ). Ambas se proclamaron ganadoras y provocaron la división de la CGT.

56. CGT (1942), Actas de reuniones del Comité Central Confederal, Buenos Aires. 
entre la política y la acción sindical en un escenario político que exigía tomar una posición clara en el universo político.

\section{A modo de cierre}

La articulación entre la problemática local y el movimiento obrero nacional así como también las tensiones entre las configuraciones políticas e ideológicas de los sindicatos, representan dos de las aristas más sugerentes para entender las experiencias obreras en el interior. En esa dinámica, tanto por enfrentamiento como por adhesión, se fueron configurando los cambiantes mapas de alianzas que dieron forma a los intentos de unidad. En esa dirección, el vínculo de los gremios con los partidos obreros fue un eje nodal de desacuerdos que fue tallando una dinámica de encuentros y conflictos cada vez más acalorada. La política o su contracara, la prescindencia, fue el factor más discordante, ya que en un escenario provincial, era la politica la que permitia construir poder y, asimismo, afianzarse por fuera del mundo del trabajo. Estas discusiones se planteaban desde lo local y lo nacional, pero también se explicaban por una clave internacional de conflicto que gravitó con fuerza durante los años 30, adquiriendo diversos nombres: fascismo/ antifascismo, imperialismo/antiimperialismo, libertad y democracia/ reacción.

Las divisiones entre los agrupamientos en Tucumán reprodujeron políticamente aquellas divisiones entre bandos políticos que se daban a nivel nacional, sin embargo, desde lo sindical conservaron cierta autonomía. Por eso, en un principio, la construcción de centrales sindicales de la provincia respondió a procesos regionales. Sin embargo, a tono con los cambios organizativos en el mundo sindical -la consolidación de estructuras por industria, federaciones y uniones- que fueron perfilando un nuevo modelo de lucha obrera, se fueron también condicionando las formas de unidad. En el mediano plazo, esas primeras iniciativas fueron siendo cooptadas y disciplinadas tanto por sus direcciones porteñas, como por la CGT.

Los incipientes intentos del primer lustro confluyeron en la FPT, donde se encarnaba las disputas y balances locales de poder y se respetaban las construcciones autóctonas. La FPT visibilizó un movimiento obrero más consolidado, con sus rituales y sus formas de acción. Sin embargo, en el marco de las reestructuraciones sindicales de la década se fue construyendo un cierto consenso entre algunas organizaciones respecto a que la dinámica de negociaciones gremiales ya no podia estar concentrada en un ámbito regional acotado y era necesario, por lo tanto, extender la capacidad de articular demandas.

La CGT había gravitado siempre sobre el escenario obrero local; 
pero fue recién a fines de la década cuando decidió disputar y construir seriamente con los espacios locales. Así, comenzó a diseñar una política verdaderamente nacional presionando por instalarse como la ejecutora de ese nuevo mapa sindical que también incorporaba a los trabajadores del azúcar, rueda maestra de la economía tucumana. Su desembarco definitivo en la provincia vino a desarticular las claves de poder local y asimismo las trayectorias históricas de los sindicatos tucumanos. La disputa numérica y la capacidad de movilización local ya no servian para disputar poder. Por otro lado, la CC tampoco fue ajena a los enfrentamientos que se venían desarrollando durante la década ni a las rispideces entre los partidos y los gremios que empezó a gravitar con fuerza en el mundo obrero de la década del 30. Pero sí encarnó y fue consecuencia de las nuevas circunstancias del mundo sindical del país: la extensión de las federaciones y uniones, el crecimiento y fortalecimiento de la trama de vínculos gremiales, la centralización de las políticas y la necesidad de gestionar asuntos desde la Capital Federal, en un contexto político, social y económico que se volvía dificil para la acción gremial tras el ascenso del presidente Castillo a la presidencia.

La clase obrera tucumana, o sus dirigentes, fueron tejiendo un paño de alianzas y disputaron politicamente las organizaciones que terminaron de dar forma al escenario sindical y político de la provincia. En definitiva, en este espacio acotado, se pueden observar, a través de las trayectorias de unidad, las discusiones, los debates y dificultades que atravesó el movimiento sindical argentino durante los años 30 y sus particularidades regionales. Unos meses después, el golpe de Estado de 1943 y la consolidación de la Federación Obrera de la Industria Azucarera con un poder de movilización inmensamente superior al del total de los gremios locales, cambiarian todas las reglas del juego.

\section{Bibliografia}

Borlenghi, Ángel (1943), "La verdad sobre lo sucedido en la CGT. Propuesta de solución", Buenos Aires: Confederación de Empleados de Comercio de la República Argentina.

Camarero, Hernán (2011), "La izquierda partidaria y la CGT, 1935-1939. Las disputas entre el frentepopulismo comunista y la prescindencia apolítica de la dirección sindicalista", en Actas de las XIII Jornadas Interescuelas/ Departamentos de Historia, Catamarca, agosto.

- (2012) "Alcances del sindicalismo único por rama antes del peronismo: la experiencia de la Federación Obrera Nacional de la Construcción (FONC), 1936-1943", Estudios del Trabajo, no 43-44.

Del Campo, Hugo (2005), Sindicalismo y peronismo. Los comienzos de un vínculo perdurable, Buenos Aires: Siglo XXI. 
Di Tella, Torcuato, (2003) Perón y los sindicatos, Buenos Aires: Ariel.

Doyon, Louise (2006), Perón y los trabajadores. Los orígenes del sindicalismo peronista, 1943-1955, Buenos Aires: Siglo XXI.

Horowitz, Joel (2004), Los sindicatos, el Estado y el surgimiento de Perón, 1930-1946, Buenos Aires: Eduntref.

Kindgard, Adriana (2000), “Jujuy: ¿Quiebre de la deferencia o relajamiento de la coerción en los años de transición al peronismo? A propósito de procesos sociopolíticos nacionales y conflictividad regional", Actas de las XVII Jornadas de Historia Económica, Tucumán.

Martínez, Ilana (2009), "Conflictos, disidencia y radicalización. El ala de izquierda del Partido Socialista Argentino, 1929-1937", en Actas II Jornadas Nacionales de Historia Social, La Falda.

Matsushita, Hiroshi (1983), Movimiento obrero argentino, 1930-1945, Buenos Aires: Siglo Veinte.

Murmis, Miguel y Portantiero, Juan Carlos (2004), Estudios sobre los orígenes del peronismo, Buenos Aires: Siglo XXI (ed. definitiva).

Torre, Juan Carlos (2006), La vieja guardia sindical y Perón. Sobre los orígenes del peronismo, Buenos Aires: Eduntref.

Ullivarri, María (2008), "El Partido en su laberinto. La Federación Socialista Tucumana, 1931-1937”, Historia Regional, ISP N³, año XXI, n 26.

- (2010), Trabajadores, sindicatos y politica en Tucumán, 1930-1943, tesis de doctorado, Universidad de Buenos Aires.

Zimmermann, Eduardo (1985), "Sindicatos y política en Argentina (19001943)", Libertas, no 2, mayo.

Resumen: El objetivo de este trabajo es analizar las trayectorias de unidad de los sindicatos de la provincia de Tucumán, buscando dar cuenta de los procesos de construcción de centrales obreras en los espacios regionales en los años 30. Para ello se hará especial hincapié en las articulaciones politicas locales, los vínculos intergremiales y en las relaciones con las centrales nacionales, especialmente la Confederación General del Trabajo.

Palabras clave: centrales obreras - Tucumán - politica - CGT.

Abstract: The aim of this paper is to analyze the course of unity among unions from the province of Tucumán, seeking to account for the processes of building trade union federations in the regional spaces in the ' 30 s. To achieve that, we will make special emphasis on the links between unions, the political discussions among them, and the relationships with national federations, especially the General Confederation of Labor.

Keywords: Union federations - Tucumán - politics - CGT.

Recepción: 6 de enero de 2014. Aprobación: 27 de febrero de 2014 . 